\title{
The urgency of wider adoption of one health approach for the prevention of a future pandemic
}

\author{
M. Nazmul Hoque ${ }^{1,2+}$ (D), Golam Mahbub Faisal2+(i), Farhan Rahman Chowdhury ${ }^{3}$ id, Amlan Haque ${ }^{4}$, and Tofazzal Islam³ \\ 1. Department of Gynecology, Obstetrics and Reproductive Health, Faculty of Veterinary Medicine and Animal Science, \\ Bangabandhu Sheikh Mujibur Rahman Agricultural University, Gazipur, Bangladesh; 2. Faculty of Veterinary Medicine \\ and Animal Science, Bangabandhu Sheikh Mujibur Rahman Agricultural University, Gazipur, Bangladesh; 3. Institute \\ of Biotechnology and Genetic Engineering, Bangabandhu Sheikh Mujibur Rahman Agricultural University, Gazipur, \\ Bangladesh; 4. School of Business and Law, CQUniversity, Sydney Campus, Australia.
}

${ }^{+}$Contributed equally to this work.

Corresponding author: Tofazzal Islam, e-mail: tofazzalislam@bsmrau.edu.bd

Co-authors: MNH: nazmul90@bsmrau.edu.bd, GMF: golammahbub00@gmail.com, FRC: flightbulbs@gmail.com, AH: ajhaque@gmail.com

Received: 27-09-2021, Accepted: 10-01-2022, Published online: 23-02-2022

doi: www.doi.org/10.14202/IJOH.2022.20-33 How to cite this article: Hoque MN, Faisal GM, Chowdhury FR, Haque A, Islam T (2022) The urgency of wider adoption of one health approach for the prevention of a future pandemic, Int. J. One Health, 8(1): 20-33.

\begin{abstract}
Recurring outbreaks of emerging and re-emerging zoonoses serve as a reminder that the health of humans, animals, and the environment are interconnected. Therefore, multisectoral, transdisciplinary, and collaborative approaches are required at local, regional, and global levels to tackle the ever-increasing zoonotic threat. The ongoing pandemic of COVID-19 zoonosis has been posing tremendous threats to global human health and economies. The devastation caused by the COVID-19 pandemic teaches us to adopt a "One Health Approach (OHA)" to tackle a possible future pandemic through a concerted effort of the global scientific community, human health professionals, public health experts, veterinarians and policymakers through open science and open data sharing practices. The OHA is an integrated, holistic, collaborative, multisectoral, and transdisciplinary approach to tackle potential pandemic zoonotic diseases. It includes expanding scientific inquiry into zoonotic infections; monitoring, and regulating traditional food markets, transforming existing food systems, and incentivizing animal husbandry and legal wildlife trade to adopt effective zoonotic control measures. To adopt an OHA globally, research and academic institutions, governments and non-government sectors at the local, regional, and international levels must work together. This review aimed to provide an overview of the major pandemics in human history including the COVID-19, anthropogenic drivers of zoonoses, Severe Acute Respiratory Syndrome Coronavirus-2 (SARS$\mathrm{CoV}-2$ ) reverse zoonoses, the concept of OHA and how an OHA could be utilized to prevent future pandemic threats to the human-animal-ecosystem interfaces. In addition, this review article discusses the strategic framework of OHA and possible challenges to implement OHA in practice to prevent any future pandemics. The practices of open data sharing, open science, and international collaboration should be included in the OHA to prevent and/or rapidly tackle any health emergencies in the future.
\end{abstract}

Keywords: COVID-19, future pandemic, one health approach, prevention.

\section{Introduction}

Pandemics are large-scale outbreaks of infectious diseases that can significantly increase morbidity and mortality over a wide geographic area and cause significant economic, social, and political disruption. There have been many significant pandemics recorded in human history, and the pandemic-related crises have caused enormous negative impacts on health, economies, and even national security in the world. The outbreak of severe acute respiratory syndrome (SARS) [1] and Middle-East respiratory syndrome (MERS) [2] in 2002-2003 and 2012, respectively, have caused deadly illnesses. A novel coronavirus, popularly termed SARS Coronavirus-2 (SARS-CoV-2),

Copyright: Hoque, et al. This article is an open access article distributed under the terms of the Creative Commons Attribution 4.0 International License (http://creativecommons.org/licenses/ by/4.0/), which permits unrestricted use, distribution, and reproduction in any medium, provided you give appropriate credit to the original author(s) and the source, provide a link to the Creative Commons license, and indicate if changes were made. The Creative Commons Public Domain Dedication waiver (http:// creativecommons.org/ publicdomain/zero/1.0/) applies to the data made available in this article, unless otherwise stated. surfaced in Wuhan province of China in December 2019 [3,4], nearly 7 years after the MERS 2012 epidemic, has led to a dramatic loss of human life worldwide and presents an unprecedented challenge to public health, food systems, and the world of work. The ongoing COVID-19 has developed to be one of the fatal pandemics of the past 100 years after the Spanish Flu of 1918 [5], and possibly stems from zoonotic origins. As of January 29, 2022, COVID-19 has affected around 370 million people across the planet, killing over 5.7 million people, and sending billions into home-lockdowns (https://www.who.int/es/emergencies/diseases/novel-coronavirus-2019/advice-forpublic). Considering its unprecedented global spread and severity, the World Health Organization (WHO) declared the COVID-19 outbreak as a 'Global Health Emergency' on January 30, 2020 [6], and later - a disease of international concern (pandemic) on March 11, 2020 [3]. The contagiousness of the SARS-CoV-2 infection explains the rapid growth of the outbreak into a pandemic, expressed by the circulating strain heterogeneity and broad host range [7], and thus, has 
brought the importance of pandemic preparedness and response.

Since its emergence, there has been intense interest in understanding how SARS-CoV-2 emerged in the human population. Recent debate has coalesced around two competing ideas: A "laboratory escape" scenario and zoonotic emergence. Phylogenetic evidence shows that the genome SARS-CoV-2 is $96 \%$ identical to an Old-World bat $\mathrm{CoV}$, BatCoV, and RaTG13 of Rhinolophidae $[4,8]$. SARS-CoV-2 mink-associated variant strain has also been identified in mink farms in Denmark [9]. Although there is no convincing evidence of SARS-CoV-2 transmission from bats to people, the whole genome of an intermediate horseshoe bat (Rhinolophus affinis) shares the closest relative $(96.2 \%)$ sequence similarity with the genomes sequence of the SARS-CoV-2, suggesting the possible source of origin [3].

Moreover, intermediate hosts such as civets and camels were essential to both SARS-CoV and MERS$\mathrm{CoV}$ [8], which indicates the possibility of SARS$\mathrm{CoV}-2$ being transmitted to humans by other animals. Remarkably, one pioneering research reported that Pangolin-CoV also showed $91 \%$ genome identity with the SARS-CoV-2 at the whole-genome level [8]. One of the retrospective studies that analyzed over 300 infectious episodes between 1940 and 2004 [10] identified wildlife as the major source of emerging infections. Detailed understanding of how SARS-CoV-2 jumped species boundaries to infect humans is shown in Figure-1. Despite the significant roles of wildlife in a zoonotic disease outbreak, only humans and economically important animal species have remained the main focus of research.

The World Organization for Animal Health (OIE), Caceres et al. [11] estimated that (i) $60 \%$ of existing human infectious diseases are zoonotic; (ii) above $75 \%$ of emerging infectious diseases (EIDs) of humans have originated from animal sources; (iii) every year five new human diseases appear, and of them, three are of animal origin; and (iv) zoonotic pathogens may comprise as much as $80 \%$ potential bioterrorism agents. Therefore, the cross-talk and interactions among emerging pathogens, their hosts, and the corresponding environment are vital to our understanding of the EIDs and their treatment and prevention $[11,12]$. Emerging zoonotic diseases pose a huge global health burden [13]. Some of them affect a large number of people within a region (epidemic), and others spread over several countries (pandemic) around the globe affecting large numbers of people [14]. The adverse effects of emerging zoonoses on human health and economies have recently been highlighted by outbreaks of the Nipah virus [15], MERSCoV [16], and SARS-CoV [17]. In addition, the zoonotic diseases that are persistent in many impoverished populations, thus called "neglected zoonoses," still received much less attention and research or prevention grants from local, regional, and international levels than emerging zoonotic diseases [18]. Evidence

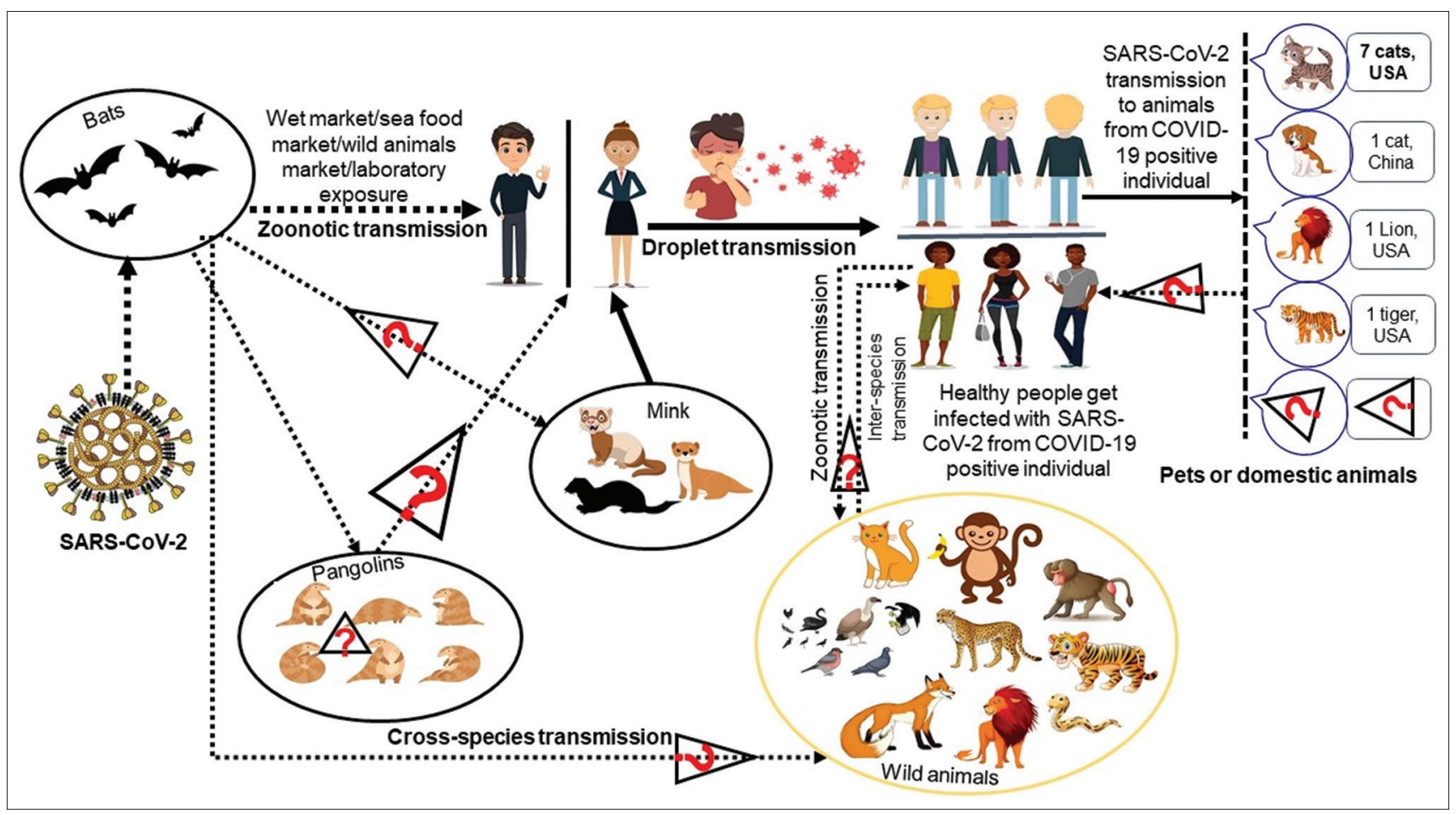

Figure-1: The possible mode of transmission of severe acute respiratory syndrome coronavirus-2 (SARS-CoV-2). Bats can act as primary reservoirs for novel coronavirus; SARS-CoV-2. SARS-CoV-2 may cross the species barrier into pangolins, in wild and other live-animals in seafood/wet market. Consumption of infected animals as food items is the major source of infection transmission in humans, and human-to-human transmission through droplets/fomites, which results in community transmission as well as human-to pet animal spread. Dotted arrows show the possibility of virus spread from bat to animals or humans, whereas the solid black arrows indicate confirmed transmission of the virus. [The figure was generated using Microsoft PowerPoint and Adobe Illustrators]. 
suggests that the occurrence of pandemics has risen over the past 100 years due to increased global travel and integration, urbanization, changing patterns of land usage, and increasing exploitation of the natural environment [19]. If these issues are not addressed, these trends will likely continue and intensify in the coming years. Despite the progress made by the international community, there remains significant ground to be covered [20].

The One health approach (OHA) based on the lessons learned from the preceding and current pandemic outbreaks, might be a solution to halt the progression of emerging zoonotic diseases [20,21]. One health $(\mathrm{OH})$ aims to improve human-health issues by working at its root, which it believes to be intertwined with the health of the animals around us and our shared environment. $\mathrm{OH}$ acknowledges that EIDs originate from wild animal reservoirs because of a few strong anthropogenic drivers that include a high growth rate of the human population, land use patterns, and natural resource depletion [14]. However, implementing OHA in practice is still a challenging task. Most countries lack multi-sectorial (e.g., human health, animal health, agricultural, and environmental sectors) coordination and integration activities as these sectors traditionally have different mandates [22]. As a result, the practical application of OHA remains unattained.

Globally, there is recognition for the concept of OHA, which has led to the establishment of several $\mathrm{OH}$ initiatives around the world, including the U. S. National Park Service One Health Initiative, Centers for Disease Control and Prevention One Health Office, U. S. National Institute of Health, United States Department of Agriculture One Health Coordination Center, coordinated multisectoral mechanisms (such as Bangladesh's One Health Secretariat and Liberia's One Health Coordination Platform), international One Health establishments (e.g., the Food and Agriculture Organization (FAO)/OIE/WHO Tripartite collaboration, Southeast Asia One Health University Network, One Health Central and Eastern Africa), and education programs that concentrates on $\mathrm{OH}[14,23]$. The Global Health Security Agenda was launched in 2014 to unite countries to uphold OHAs and improve our ability to prevent, detect, and respond to zoonotic disease threats [24]. The US Agency for International Development launched the Emerging Pandemic Threats Program; PREDICT Project in 2009 [19] to strengthen global capacity for detection of viruses with pandemic potential that can move between animals and people, and the development of effective responses to those potentially zoonotic viral threats at their source, utilizing the OHA.

Cooperation and sharing data between different nations are the fastest way to accrue valuable knowledge that may help us prepare for future challenges [25]. The current COVID-19 pandemic has revealed the vital importance of open science and data sharing for effective emergency preparedness and response [26]. Since the start of the pandemic, different SARS-CoV-2 gene sequences have been shared openly through different open data-sharing platforms such as National Center for Biotechnology Information, Global Initiative on Sharing All Influenza Data, and Nextstrain (https://nextstrain. org). These platforms provided the data that allowed scientists to decode the different properties of the SARS-CoV-2 and find the proper countermeasures, including vaccines and supportive therapeutics. Even though vaccine and medication technologies are at pace with significant advancement for the treatment, prevention, and control of various diseases outbreaks, in many cases reactive outbreak responses have incurred high financial costs. Regardless of its strong motivating rationale, implementing OHA can be challenging for a future pandemic as well. Therefore, this literature survey aims to review driving forces associated with outbreaks of zoonotic diseases and discusses how OHA could be globally adopted to prevent the possible emergence of a new pandemic.

\section{Rationale and Review Methods}

\section{An overview of the past pandemics}

COVID-19 has alerted the world to the catastrophic potential for spillover of zoonotic diseases and health risks at the human-animal-environment interface. The global pandemic has also reaffirmed the need for a joint, global approach to prevent EIDs. A zoonosis is a communicable disease that spreads from non-human animals to humans [18]. It can lead to millions of deaths along with thousands of billions of dollars in economic losses annually [27]. Historic zoonotic disease outbreaks include the Zika virus disease, Ebola virus disease, MERS, the $2009 \mathrm{H} 1 \mathrm{~N} 1$ pandemic or Swine Flu, SARS, the Smallpox epidemic in the former Yugoslavia, human immunodeficiency viruses/ acquired immunodeficiency syndrome, Spanish Flu, New World Smallpox, the Black Death (Bubonic Plague), the Justinian Plague, and the Antonine Plague (Table-1) [4,16,28-38]. The Black Death is considered the "First Great Pandemic of History," which ravaged the death of 75-200 million people in Eurasia and North Africa, peaking in Europe from 1347 to 1351 (Table-1). The avian originated 1918 influenza pandemic popularly known as the "Spanish Flu" was the most severe in recent history [5,39], about 500 million people or one-third of the world's population became infected with this virus, of which at least 50 million died worldwide [39]. The 2002-2004 SARS outbreak caused by the SARS-CoV infected thousands of people [40], and almost a decade later, the world saw the outbreak of another zoonotic disease, MERS, caused by the MERS-CoV, which had a significantly higher fatality than SARS [16]. Both SARS and MERS have a zoonotic origin from bats [41].

Many reports covering various aspects of recent pandemics, including SARS, MERS, and SARS$\mathrm{CoV}-2$ have been published. However, an inclusive 


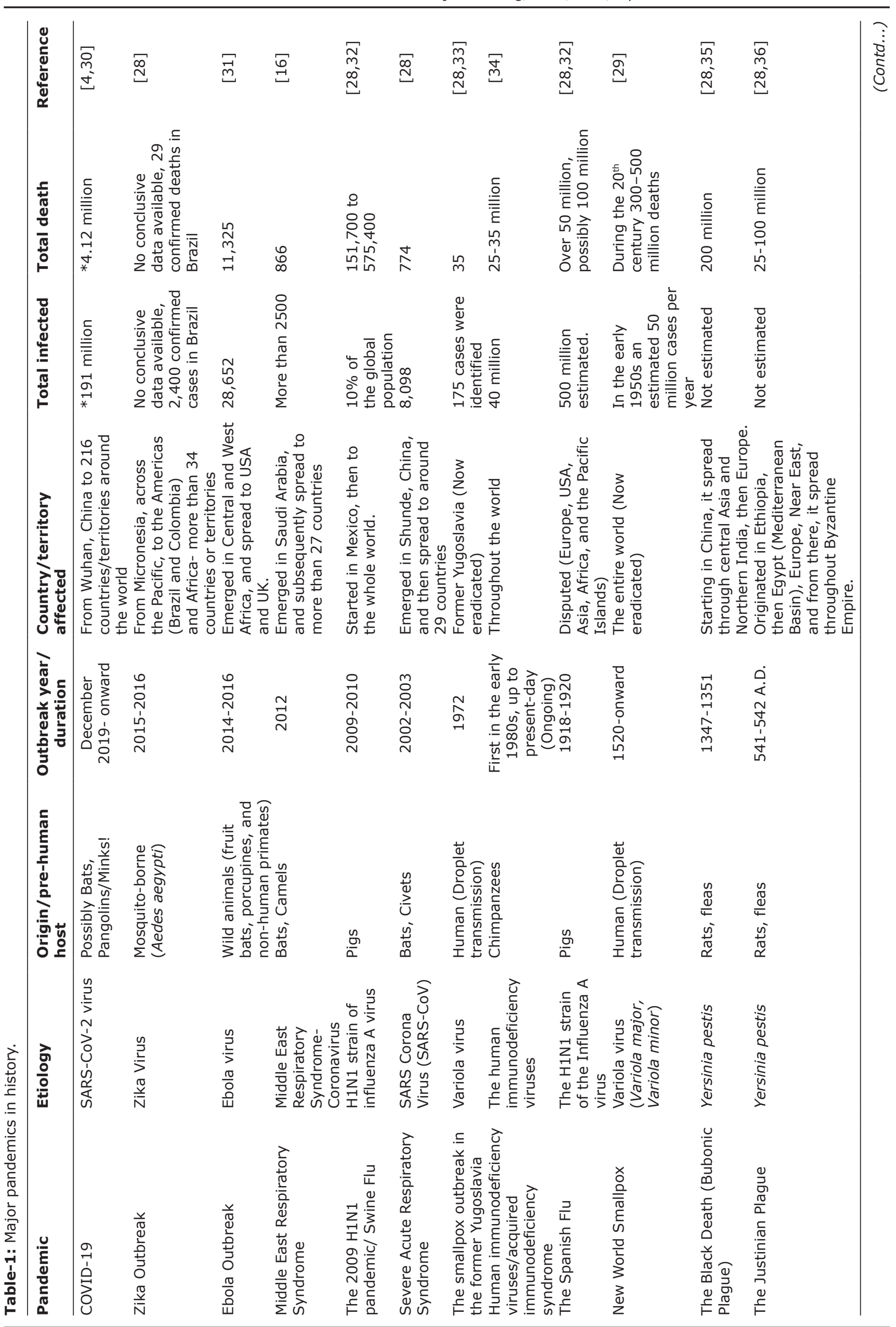




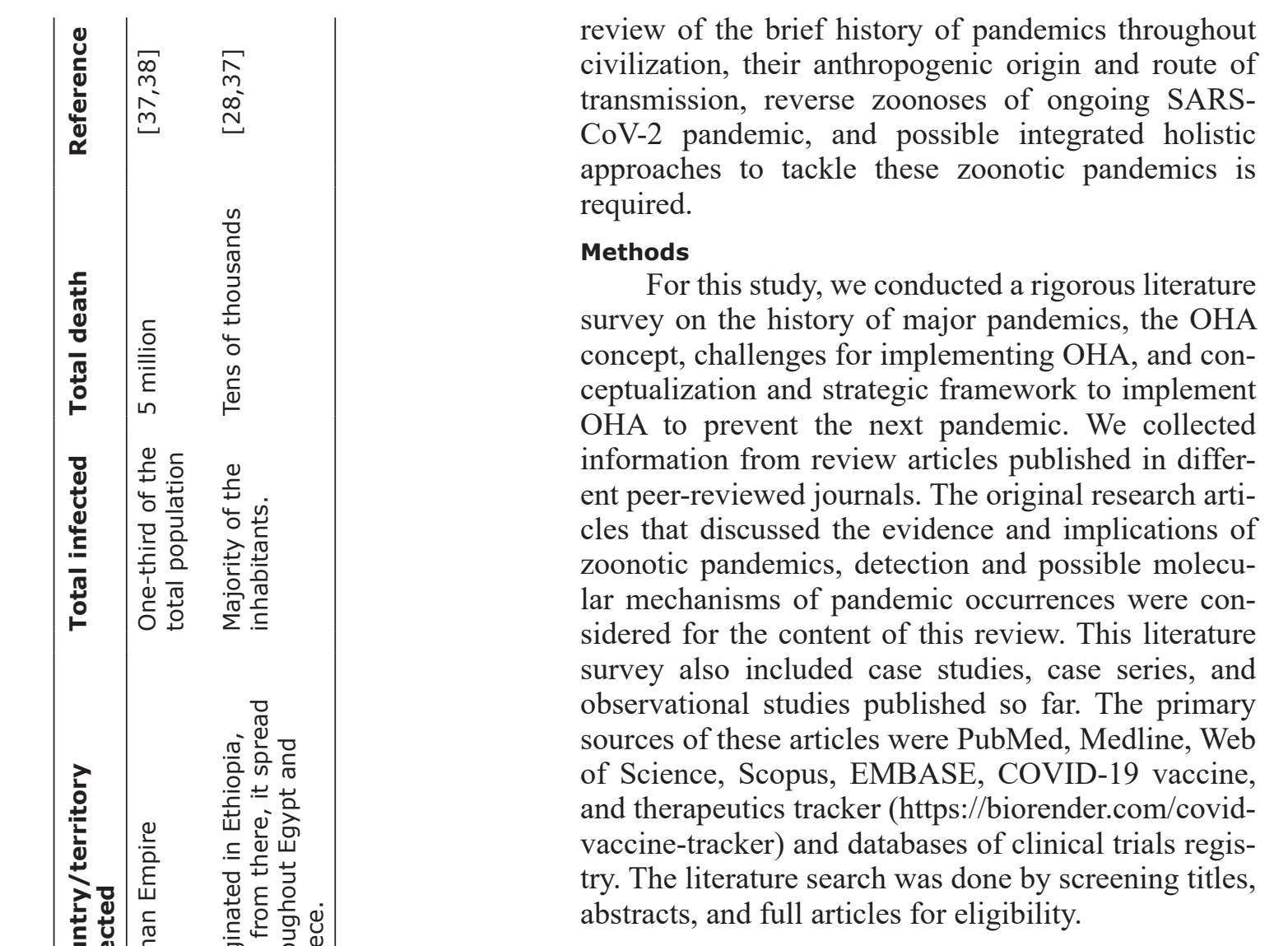

review of the brief history of pandemics throughout civilization, their anthropogenic origin and route of transmission, reverse zoonoses of ongoing SARS$\mathrm{CoV}-2$ pandemic, and possible integrated holistic approaches to tackle these zoonotic pandemics is required. survey on the history of major pandemics, the OHA concept, challenges for implementing OHA, and conceptualization and strategic framework to implement A to prevent the next pandemic. We collected information from review articles published in different peer-reviewed journals. The original research articles that discussed the evidence and implications of onotic pandemics, detection and possible molecuconurvey also included case studies, case series, and observational studies published so far. The primary sources of these articles were PubMed, Medline, Web of Science, Scopus, EMBASE, COVID-19 vaccine, and therapeutics tracker (https://biorender.com/covidtry. The liter

\section{Anthropogenic Drivers of the Zoonotic Disease} Outbreaks

Zoonotic diseases established or periodically circulate in certain populations are responsible for a billion cases and millions of human deaths annually. The majority of EIDs (and almost all recent pandemics) originate in animals, mostly wildlife, and their emergence often involves dynamic interactions among populations of wildlife, livestock, and people within rapidly changing environments. It has been reported that about $60 \%$ of global IEIDs are zoonotic [42]. More than 30 new human pathogens have been detected in the last three decades, $75 \%$ of which have originated from animals or animal products $[43,44]$. The conspicuous emergence of human pandemics from the animal population has increased public awareness of animal and human health links. The human population has escalated from about 1.6 billion in 1900 to about 7.8 billion [43], and the population of domesticated or peri-domestic animals (such as rats) that thrive in the new and modified environments also increased in parallel. This has, in turn, played a major part in the reduction of wildlife populations but paradoxically increased contact between people and animals. The dramatic increase in human population, mobility, and the associated social and environmental changes have contributed to the recent upsurge in the incidence of EIDs and emerging zoonotic pathogens $[4,28,45,46]$. Zoonotic diseases demised the lives of about two million people from low/middle-income countries every year [47]. The Global Virome Project (GVP) recently estimated that $631,000-827,000$ unidentified viruses 
exist with zoonotic potential (https://www.globalviromeproject.org/). Even with a growing understanding of how species leaps happen, precise zoonoses outbreak predictions are not guaranteed. According to a recent joint effort report by the United Nations Environment Program (UNEP) and the International Livestock Research Institute (ILRI) [43], and currently available literature, there are seven drivers of zoonotic disease emergence, all of which are associated with the human interaction with animals and encroach into the natural world. The anthropogenic factors that are implicated in the origin of pathogens or the jump of one pathogen/microbe to another host to rendering the emergence of zoonotic infectious diseases are discussed in the following sub-sections.

\section{Increasing demand for animal protein}

Wild animal consumption is an important driver of new zoonoses [48], and consumption of animal meat containing pathogens may give rise to diseases in humans. The ever-increasing demand for animal protein, fuels unsustainable livestock farming that harms the natural environment and is one of the most important causes of the rising frequency of zoonotic diseases. Numerous infectious diseases, including some now confined to humans, have established themselves in human populations through domestic animals in the past (e.g., smallpox and tuberculosis).

\section{Increased deforestation}

Deforestation, forest fragmentation, and afforestation are all alterations in habitat, which change species composition and the interaction between wild animals, domestic animals, insect vectors, and humans, providing new opportunities for microbial transmission and potential emergence. Increasing demand for food from animal sources encourages the industrialization of animal products, leading to widespread deforestation and destruction of biodiversity, and is one of the root causes of zoonotic pathogen emergence [49].

\section{Increased use and exploitation of wildlife}

Wild animals are an important source of food (bushmeat) in some developing countries and bushmeat has been implicated in the emergence of HIV, and the spillover of monkeypox, Nipah, Ebola, anthrax, and Simian foamy viruses [48]. Harvesting wildlife, bushmeat consumption, and wildlife trade are some of the important drivers of new zoonoses. It is estimated that about $72 \%$ of zoonotic pathogens have their origins in wildlife [48], and increased human-wildlife interactions in the form of the hunting and consumption of animal products are important sources of zoonotic contamination.

\section{Urbanization and human behavior}

Between 2011 and 2050 the world population is expected to increase by 2.3 billion (a $32 \%$ increase), and the increase will be concentrated in urban areas of developing countries. Urbanization is one facet of changing human sociocultural systems, including changing consumer demands and dietary habits. Extensive urbanization can bring wildlife closer to livestock and humans and alter disease ecology [50]. Human activities that increase interaction between humans and wild animals will surely increase the risk of the emergence of zoonotic pathogens. However, the underlying epidemiological processes by which this occurs are not clearly understood. In addition, global biodiversity losses due to urbanization generally increase wildlife and zoonotic infections of humans [51].

\section{Travel and transportation}

Due to human movements, infectious agents and/or diseases can now spread throughout the world in extremely short periods, often quicker than their incubation periods (the time amid exposure to a pathogen and the first onset of clinical signs). Human travel associated with tourism, business, and other moves not associated with changing residence has increased rapidly over the past 50 years and are projected to continue to grow [50]. Travelers are not only at risk of contracting communicable diseases when visiting tropical countries, but they may also act as carriers for spreading infectious diseases, as has been the case for SARS, MERS, and SARS-CoV-2.

\section{The changing food supply chains}

Lengthening and evolving food supply chains have been inevitable due to the ever-changing and increasing demand for animal products and exotic wildlife foods, which creates new opportunities for transmission of zoonotic pathogens. With the global food demand predicted to increase drastically by the year 2100 , the potential for the rise of new zoonotic infections and the rate of spread of these infections will undoubtedly increase. Moreover, increasing meat and bushmeat consumption also contribute to biodiversity loss as it disrupts food chains in natural habitats and leads to what is commonly known as "empty landscapes" [48].

\section{Climate change}

The WHO declared that climate change and global warming are the most significant challenges for humankind in the $21^{\text {st }}$ century [52]. Climate changes influence cholera, malaria, diarrhea, or dengue fever outbreaks [53]. Climate change can also modify human socio-demographics and move humans and livestock from dry, hot areas to new geographic locations [54]. This is accompanied by changes in the concurrent geographical distribution of wild animals and insects [52]. The epidemiological relationship and interaction between climate changes, disruption of ecosystems, exposure of humans and livestock insects that carry pathogens, and the spread of zoonoses is well documented [52-54].

\section{Reverse Zoonosis of SARS-CoV-2: New Perspectives on the Human-animal Interface}

Zoonotic pathogens can jump from an animal reservoir to a human host (Figure-1), either transmitted 
directly or through insect vectors [55]. When the pathogen is transmitted from humans to animals, it is called reverse zoonosis or zooanthroponosis. The animal infected through the process may, in turn, re-transmit the infection to humans under some circumstances. Humans have a long history (more than several decades) of relationships with animals as a part of animal husbandry practices, the growth of the pet market, changes in climate and the environment, changes in ecosystems, modification of habitats due to anthropogenic factors, and global travel and commerce [55]. Human-to-animal transmission is plausible for many diseases because the pathogens concerned are known to infect multiple species. Studies suggestive of transmission of human parasites to animals were first published in 2000. The most commonly reported parasitic agents transmitted from humans to animals were Giardia duodenalis and Cryptosporidium parvum [56]. Researchers discovered the human strain of pandemic Escherichia coli strain 025:H4-ST131 CTX-M-15 in many different species of animals, indicating inter-species transmission from humans to pets and livestock [56,57]. The global scale transmission of the H1N1 virus from pigs to humans is known to date to represent the largest "reverse zoonosis" of a pathogen [58]. Many confirmed cases of humans with the influenza virus infecting their pets exist (ferrets, cats, and dogs) [59].

The milieu of cohabitation between humans, dogs, and cats has developed relationships among which few infectious agents are routinely transmitted. Even though the origin of the SARS-CoV-2 virus is still unclear, evidence from genetic studies suggests that bats act as a reservoir, with pangolins being a probable intermediate (Figure-1). SARS-CoV-2 infection was reported in a mink in April 2020 in the Netherlands and subsequently in a mink farmworker. Thus, it has been established that human-to-mink and mink-to-human transmission of SARS-CoV-2 can occur [60]. Since then, minks have been reported to be infected in Denmark, the US, Sweden, Italy, and Spain [11]. Recently, amid the COVID-19 outbreak, several reports have shown that the SARS-CoV-2 virus has crossed the species barrier to infect humans and other domestic animals and pets. Moreover, a reverse zoonosis of SARS-CoV-2 is more probable since infected humans already facilitated reverse transmission to animals, including dogs, cats, and tigers [6163]. Therefore, considering the importance of reverse zoonoses, it is important to understand how zoonotic viruses like SARS-CoV-2 rapidly jump among people, animals, and ecosystems, and enter and spread in new hosts (Figure-1).

\section{The Concept of OHA}

It is increasingly clear that resolving complex global health problems requires interdisciplinary, intersectoral expertise and cooperation from governmental, non-governmental, and educational agencies. The OHA refers to a collaborative, multi-sectoral, and transdisciplinary approach - working at the local, regional, national, and global levels to achieve optimal health outcomes recognizing the interconnection between people, animals, plants, and their shared environment [64]. The concept of "OHA" was first introduced in a symposium "Building Interdisciplinary Bridges to Health in a Globalized World" at The Rockefeller University, Manhattan in 2004, reaffirmed and comprehensively updated in the Berlin Principles in $2019[21,65]$. Current human lifestyle and other anthropogenic factors make zoonotic disease outbreaks almost unavoidable. Hence, professionals and organizations believe there is a need for improved public policy models to prevent zoonoses through a preventive approach known as "OHA." Given the interconnectedness of our global community in which humans, animals, and the environmental impact on each other and do not respect geopolitical boundaries, it may be time for all countries and their neighbors to follow OHA and consider incorporating $\mathrm{OH}$ principles into their national strategic health plans.

\section{The Key Players for the Implementation of OHA}

Several identifiable factors are important for the successful execution of OHA: (i) Prudent public health interventions, which requires the working together of human, wildlife, and environmental health partners, (ii) communication and collaboration between human health professionals (doctors, nurses, public health practitioners, and epidemiologists), animal health professionals (veterinarians and agricultural workers), and environmentalists (ecologists and wildlife experts) (Figure-2), (iii) law enforcement and policymakers, and (iv) agricultural communities. Globally, three geopolitical organizations from diverse sectors: The WHO, OIE, and FAO work in tandem to implement the OHA, and indeed, the implementation of such a holistic approach requires large collaborations. Noteworthily, The Berlin Principles (2019) for OHA recommended some key points crucially relevant to the management of pandemics, including the current COVID-19 pandemic. These include (i) holistic, progressive, and adaptive approaches to combat emerging and re-emerging diseases, realizing the importance of the interplay between different animals, humans, and ecosystems; (ii) infrastructural changes should be implemented to be better prepared for pandemics, and develop an understanding of the relationships between human and animal health, and that of the environment through investment in improved technology, policy-making, and application; and (iii) quick dissemination of information between sectors and disciplines of health needs to be ensured, and coordination between governments and NGOs, and other health-related institutions should be enhanced [66].

\section{OHA to Prevent the Future Pandemic}

The OHA, accounting for the interconnectivity of humans, animals, and the environment, is an 


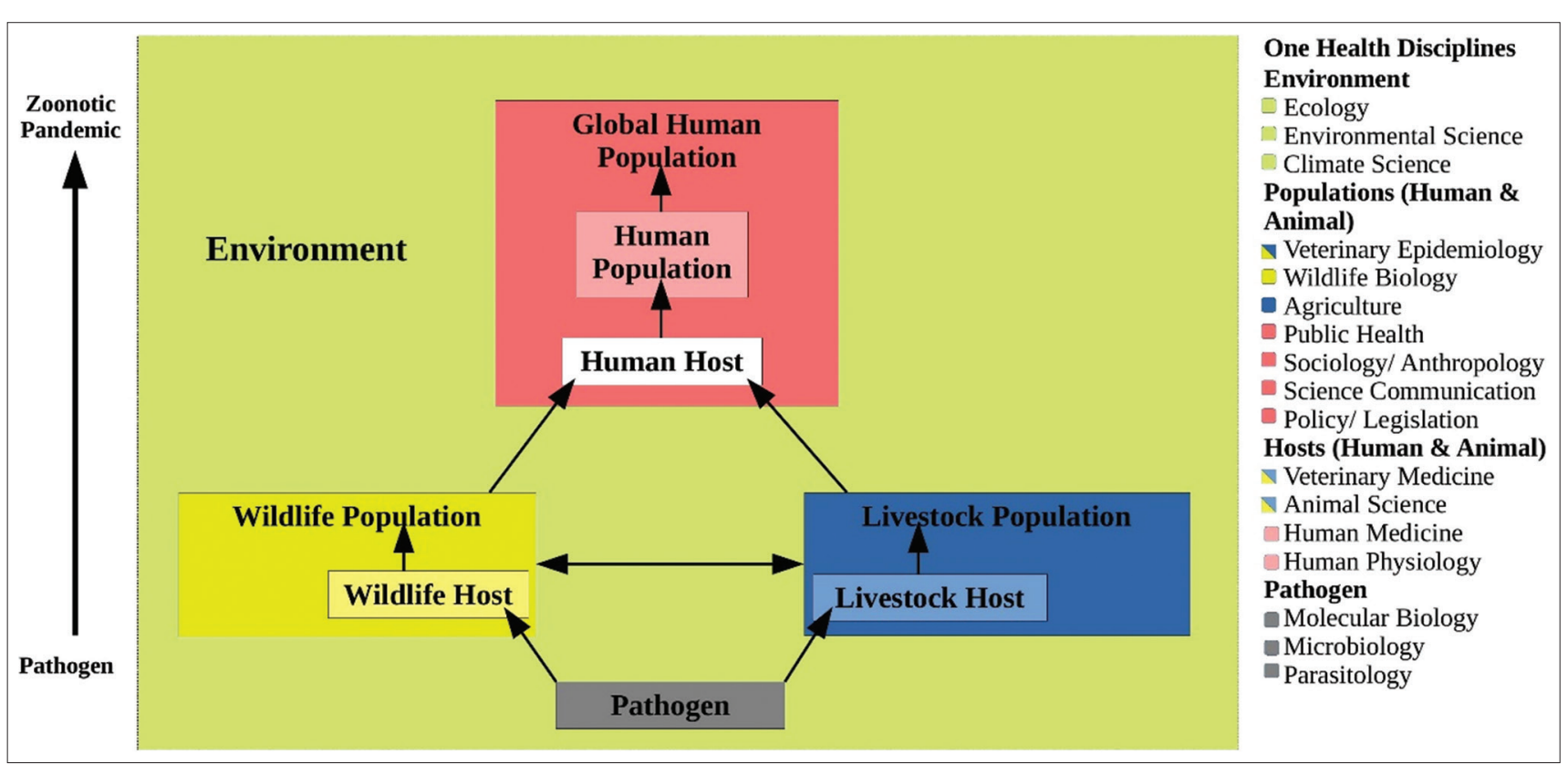

Figure-2: One Health disciplines cover the key sets in the transmission of zoonotic pathogens. Arrows indicate pathogen movement or transmission; multiple arrows indicate spread of pathogens from the initially infected host to multiple hosts through multiple transmission events; colors and patterns in the boxes adjacent to discipline names correspond to specific aspects of the pathway that each discipline typically works within [The figure was generated using Microsoft PowerPoint and Adobe Illustrator].

approach to prevent the emergence of new zoonotic reservoirs from the current COVID-19 pandemic and propose targeted interventions to tackle future pandemics. Organizations such as the WHO and FAO recommend focusing on the drivers upstream of diseases caused by zoonoses to prevent potential spillover events. It can help identify possible zoonotic pathogens that carry the risk of a possible outbreak, essentially working as an "early warning system," allowing us to develop and implement preventive measures and ready the health sector for a possible outbreak. As of World Zoonoses Day (July 06, 2020), a joint effort by the UNEP and the ILRI published a report on preventing the next pandemic after COVID-19. This paper, therefore, focuses on recommendations from the UNEP and ILRI [43] and others [67,68]. These recommendations can assist governmental organizations, businesses, and other players to respond to and prevent future disease outbreaks and reduce the risk arising due to the outbreaks. The report identifies ten important implementable steps that governments can take to prevent future zoonotic outbreaks:

Investing in interdisciplinary approaches, including OH

The $\mathrm{OH}$ paradigm has been gaining momentum over the last decades as a mechanism for cross-sectorial and interdisciplinary engagement and cooperation in health matters in its broadest sense. The advancements in health made over the past century are threatened by emerging diseases including zoonotic diseases, and hence is under pressure to reform and adapt to these challenges. Moreover, certainly, environmental and ecosystem health is an important factor that determines the health of wildlife. Hence, developing a multidisciplinary outlook that brings together and funds experts in the relevant fields and upholding the importance of environmental factors in the WHO, FAO, and OIE tripartite collaboration are urged.

\section{Expanding scientific inquiry into zoonotic diseases}

Expansion of scientific inquiry into the complex interactions between the various dimensions of society, economy, and ecology of emerging diseases to gauge the risks and develop meaningful solutions at the interface of the environment, animal, and human health.

Evaluating and improving the cost-benefit ratio of interventions to encompass complete-cost accounting of impacts of diseases on society

Improved financial analyses of emerging disease prevention interventions to encompass complete-cost accounting of impacts of diseases on society (including the cost of "side-effects" of the interventions) are suggested to be essential to enhance investments and reduce trade-offs.

\section{Raising awareness of zoonotic diseases}

Raising awareness of zoonoses through campaigning, electronic, and print media, etc., is crucial since many people do not understand the principles and risk factors underlying zoonotic diseases and require a concerted effort from the government, private, and international organizations.

\section{Implementing stricter monitoring and regulatory practices associated with zoonoses, including food systems}

Demand for animal protein has been rising globally, and global production has been steadily growing 
to keep up. Moreover, about 30 billion food animals are being maintained by about 8 billion humans worldwide [69]. Hence, strict monitoring and regulation of meat safety and quality is essential to avoid the emergence of zoonotic pathogens.

\section{Promoting sustainable management of natural resources and biodiversity}

The increasing demand for food, living space, and grazing space for animals has drastically increased deforestation. The FAO Global Forest Resources Assessment 2020 indicates the deforestation rate to be a mammoth 10 million hectares per year. This leads to the mass destruction of wildlife habitats and reduces biodiversity. The encroachment of wild animals' natural habitats by humans has also brought humans and animals into close contact, increasing the risk of animal-to-human disease transmission. Preservation of the natural barriers between wildlife reservoirs of disease pathogens and human populations, promoting ecosystem health and biodiversity through imposing strict restrictions and regulations on trade in wildlife for food will be essential in stopping the next pandemic.

\section{Improving biosecurity and control}

Identifying key drivers of EIDs, taking biosecurity measures in production-driven animal husbandry, and zoonotic disease control measures for industrial and disadvantaged smallholder farmers are all suggested to be important to lessen the prevalence and emergence of zoonotic diseases.

\section{Promoting sustainability in the management of land and seascapes}

Promoting sustainable co-existence of agriculture and wildlife through investing in food production methods that mitigate waste production and pollution while also reducing the risk of transmission of zoonotic diseases will play a pivotal role in zoonotic outbreak prevention. Conservation and restoration of wildlife habitats and realizing the importance of biodiversity in governmental and private sector decision-making and planning will be extremely important.

\section{Improving health}

The COVID-19 outbreak raises questions on the resilience of health systems and countries' emergency preparedness and response. Strengthening existing and building new capacities and investing in research in all countries to tackle health needs during outbreaks and help understand the human, animal, and environmental health dimensions of zoonotic and other diseases will be paramount to dealing with upcoming outbreaks.

\section{Operationalizing the OHA}

$\mathrm{OH}$ needs to be realized and implemented in the field-level, mediating land use, and sustainable development planning, among other fields.

Despite these broad recommendations, implementing OHAs in practice remains challenging. For instance, most countries (especially developing countries) lack clear-cut directives for coordination and collaboration between the compartmentalized governmental sectors of human health, agriculture, and environment [14]. Thus, practical implementations of OHAs have largely been need-based, causing delayed or incomplete implementation. However, more studies and assessments, and awareness-raising programs are required to demonstrate the social, health, and economic benefits to convince decision makers.

\section{Issues and Challenges for Globally Adopting the OHA}

Implementation of OHAs is often a complex issue that requires collaboration between various disciplines [70]. It is usually much more complicated at the international level and can be hindered by dysfunctions that characterize current global health governance forms. The most important aspect of implementing OHA is building sufficient science-based risk management policies that consider cross-boundary regulations. Building capacity to implement OHA is essential to quickly recognize emerging health threats. Successful development of capacity requires strengthening of networks at the global, regional, and local level and close collaboration with institutes of research, academia, cross-boundary governmental organizations, the private sector, NGOs, civil societies, and other stakeholders [71]. To implement OHA to prevent future pandemics, viewpoints of key stakeholders regarding the efforts to increase capacity, and their priorities must be given importance. A successful OHA designed for zoonotic pathogen surveillance on a global scale, and prevention of the next pandemic must include awareness building program regarding the role wildlife plays in human disease, the recognition of important human-animal interfaces, and the encouragement of science and evidence capacity building [72]. Leadership is also an important issue in the implementation of OHAs. The Tripartite collaboration between the $\mathrm{WHO}, \mathrm{FAO}$, and OIE provides a framework for building international leadership. Health-care organizations applying responsible leadership should think beyond their employee wellbeing and sustainability. For example, after tackling national challenges presented by the COVID-19 spread in Wuhan, China is sending their specialized and experienced health-care professionals to other affected countries to help overcome the global challenge of the COVID-19 pandemic presents [73,74].

It is important to recognize that $\mathrm{OH}$ requires a massively interdisciplinary approach to be successfully implemented. In the past decade, the $\mathrm{OH}$ movement has been driven primarily by veterinarians; however, involving professionals in human health and the public health sector in developing countries is a big challenge that $\mathrm{OH}$ faces [75]. There has long been a need to develop infrastructures such as interdisciplinary laboratories and structures that 
promote interdisciplinary and instrumental collaboration focused on problem-solving (e.g., childhood diarrhea linked to bovine mastitis in Rwanda). The OHA provides an opportunity for educating medical (human and veterinary) students and trainees in a system approach to extend their traditional concepts of inter-professional education [76,77]. The use of information and communication technology and modern communication channels to transfer and disseminate new and important findings is vital for mounting effective preventive measures against disease outbreaks [64]. Communication channels, networks, and scientific knowledge can be applied to human or animal health, and the knowledge and expertise to utilize these technologies have a clear $\mathrm{OH}$ dimension.

Finally, to make a globally concerted effort by engaging the global scientific community, open data sharing and open science practices have effectively tackled any health emergency. Since the emergence of SARS-CoV-2, one of the greatest contributors in the battle against this pandemic was the international sharing of information. Sequences of the SARS-CoV-2 from different countries have instantly been shared by GISAID (https://www.gisaid.org/). A large proportion of the research articles were published as preprints and all published articles were open access irrespective of the publishers. These practices have been found effective in tackling a Zika virus outbreak [78] and discovering diagnostic methods and vaccines for tackling the COVID-19 pandemic [26]. One of the salient lessons learned during the Ebola outbreak in West Africa was the importance of data sharing [79]. All research discoveries of SARS-CoV-2 outbreaks published in journals and preprint portals and sequences of the viral isolates are available in public that helped to achieve a breakthrough in the development of the diagnostic protocols and several vaccines at an unprecedented rate speed. Therefore, to rapidly tackle any emergencies in human, animal, and plant health, the practices of open data, open science, and international collaboration should be practiced $[80,81]$. The open data, open science, and international collaboration successfully tackled a plant health emergency, the wheat blast epidemic in Bangladesh in 2016 [81].

\section{Conceptualization and Strategic Framework to Implement OHA}

$\mathrm{OH}$ is a validated, integrated, and holistic approach that is being advocated by the WHO, FAO, and OIE for combating health threats to humans and animals through a human-animal-plant-environment interface. OHA aims to establish general good health and wellbeing of the public, domestic and wild animals, plants, and the environment by utilizing cutting-edge knowledge and technologies made available via researchers and their studies in public health, clinics, and other different disciplines at national and global levels. Recently, this broad idea of health in socio-ecological systems gained traction, adopting an interdisciplinary application-first stance, and joined hands with sustainability sciences $[29,82]$. However, the conceptual and institutional challenges that hinder the practical implementation of OHAs remain to be addressed, requiring an evidence base to inform policy developments effectively [83]. For example, significant efforts have been made to implement $\mathrm{OH}$ in Rwanda by adopting a three-pronged approach. This comprised collaborations at the government level, improving surveillance for early detection of emerging zoonotic pathogens, and expanding capacity for all areas, including research at the human-animal-ecosystem interface [84]. Zambia and Cambodia have utilized OHA in mitigating outbreaks of avian influenza and pandemic influenza in the past [85]. The Democratic Republic of the Congo and Tanzania strategically utilized the OHA to combat Ebola and Rift Valley fever, respectively [82].

Framework for effective implementation of $\mathrm{OHA}$ incorporates political commitment, policy formulation, sustainable financing, program development, knowledge sharing, institutional collaboration, capacity enhancement, engagement of civil society, and active participation of the communities [86]. A framework based on these principles would log case-based experiences and present the dynamics of EIDs, and promote collaboration and knowledge growth, including integration of research and survey-based knowledge on social, cultural and economic impacts, control measures, and challenges [82,87]. This strategic framework should be adaptive and responsive to change. However, strategic changes have to be fueled by support from informed political leaders (Figure-3). Robust and sustained advocacy, mainly by international partners such as FAO, OIE, and WHO, disseminating evidence-based data, projected economic gains, and best practices should be shared among the prominent national leaders [88]. The Sustainable Development Goals being intertwined offer a unique opportunity for advocacy and an integrated methodology. The political declaration by the United Nations General Assembly on combating AMR strongly recommends the OHA [88].

Another important strategy for implementing $\mathrm{OH}$ is to build an expert workforce dedicated to preparing and managing epidemiological outbreaks [84]. Similarly, efficient surveillance of both zoonotic and potential zoonotic disease must be monitored by a multidisciplinary, highly trained team. This approach will require the working together of community health workers, animal health workers, NGOs, hospitals, park rangers, farmers, and pet owners (Figure-3). OH curriculum should be embedded in different educational degrees (Undergraduate level/Masters), which promotes collaboration in problem-solving approaches in infectious disease, epidemiology, ecology, and the environment. Finally, $\mathrm{OH}$ student clubs for students can promote 


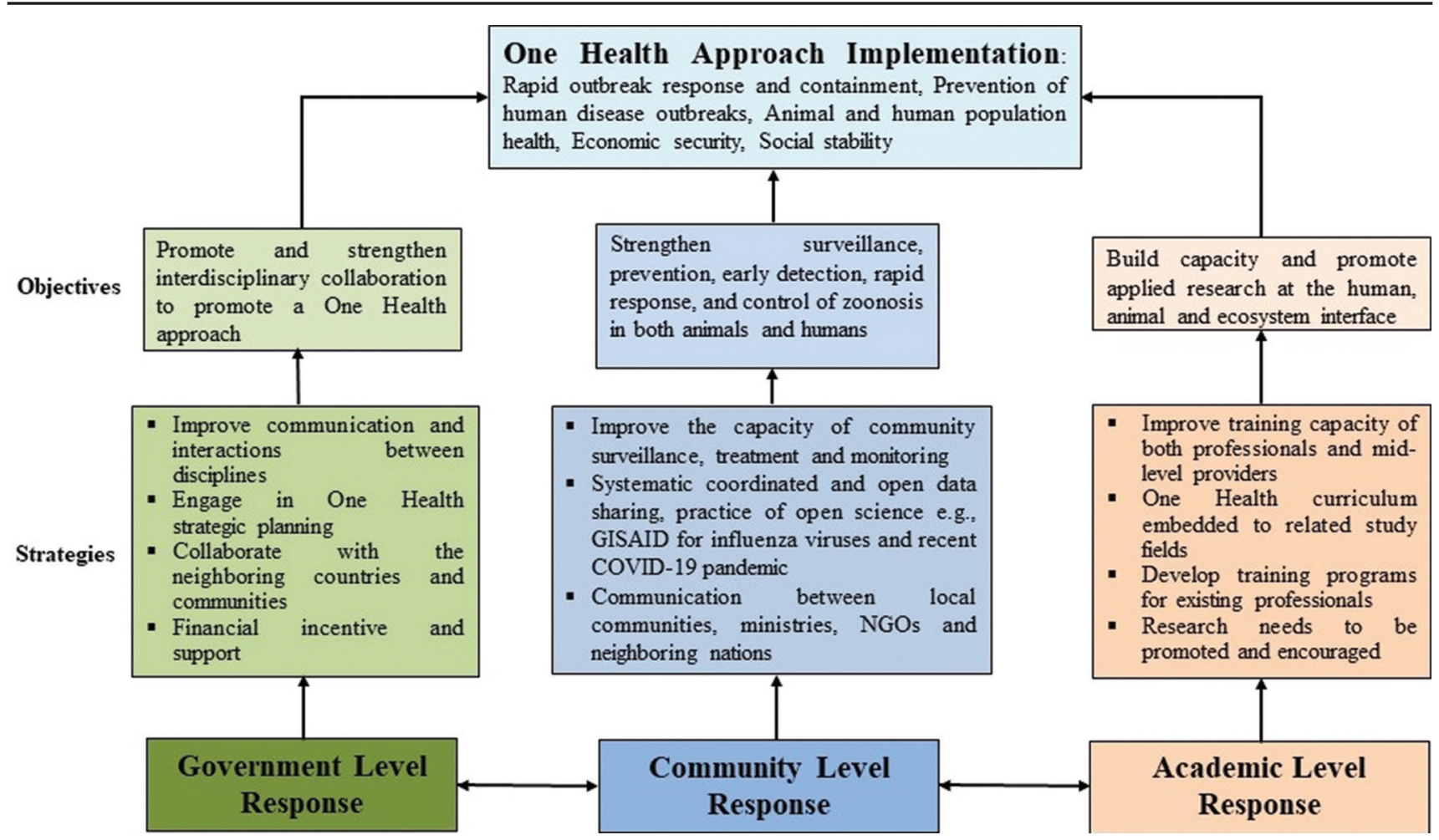

Figure-3: Schematic representation of conceptualization and strategic framework for implementation of the One Health approach. [The figure was generated using Microsoft PowerPoint].

awareness of zoonotic diseases and epidemiology, the importance of the balance and interactions between humans, animals, and the environment, and introduce $\mathrm{OH}$, approaches to a new generation of scientists and problem solvers.

\section{Conclusion}

Humankind of the $21^{\text {st }}$-century has already experienced five pandemics: SARS in 2002, "Bird flu" in 2009, MERS in 2012, Ebola in 2013-2014; and the ongoing SARS-CoV-2. The COVID-19 pandemic has affected one-third of the world's population and killed more than 50 million people. The current COVID-19 pandemic is likely to be originated from bat, mink, through pangolin, or other animal species. The OHA suggests us to look jointly at our connection with the environment and collective healths (human, animal and environmental), and to implement concerted efforts to prevent future zoonotic, epidemic or pandemic disease outbreaks. The OHA has the potential to be a holistic and systematic approach to engage the next generation in farming, agriculture, and improving public health through food safety and security, and thereby preventing diseases of zoonotic importance and public health risk. Research needs to be promoted and encouraged for a better understanding of risk management, economic implications, improving intersectoral coordination and translating global best practices into national action plans to provide policy inputs and help in the development of cost-effective interventions. This is indeed a long battle however, it can be achieved by working together with a successful implementation of the OHA.

\section{Authors' Contributions}

MNH, GMF, and TI: Conceived and designed the study. MNH and GMF: Collected review information, interpreted the findings, drafted the manuscript, and visualized the figures. FRC: Edited the manuscript. AH and TI: Critically reviewed and edited the manuscript. All authors read and approved the final manuscript.

\section{Acknowledgments}

The authors wish to thank Md Zohorul Islam, Postdoc Research Fellow, Joslin Diabetes Center/ Harvard Medical School, Harvard University, Boston, USA and Professor M. Anwar Hossain, Vice-Chancellor, Jashore University of Science and Technology, Jashore-7408, Bangladesh for their scholastic opinion and support to prepare the review.

\section{Competing Interests}

The authors declare that they have no competing interests.

\section{Publisher's Note}

Veterinary World (Publisher of International Journal of One Health) remains neutral with regard to jurisdictional claims in published institutional affiliation.

\section{References}

1. Maunder, R.G., Lancee, W.J., Balderson, K.E., Bennett, J.P., Borgundvaag, B., Evans, S., Fernandes, C.M.B., Goldbloom, D.S., Gupta, M., Hunter, J.J., McGillis Hall, L., Nagle, L.M., Pain, C., Peczeniuk, S.S., Raymond, G., Read, N., Rourke, S.B., Steinberg, R.J., Stewart, T.E., VanDeVelde-Coke, S., Veldhorst, G.G. and Wasylenki, D.A. 
(2006) Long-term psychological and occupational effects of providing hospital healthcare during SARS outbreak. Emerg. Infect. Dis., 12(12): 1924-1932.

2. Cowling, B.J., Park, M., Fang, V.J., Wu, P., Leung, G.M. and $\mathrm{Wu}$, J.T. (2015) Preliminary epidemiological assessment of MERS-CoV outbreak in South Korea, May to June 2015. Eurosurveillance, 20(25): 7-13.

3. Zhou, P., Yang, X.L., Wang, X.G., Hu, B., Zhang, L., Zhang, W., Si, H.R., Zhu, Y., Li, B., Huang, C.L. and Chen, H.D. (2020) A pneumonia outbreak associated with a new coronavirus of probable bat origin. Nature, 579: 270-273,

4. Hoque, M.N., Chaudhury, A., Akanda, M.A.M., Hossain, M.A. and Islam, M.T. (2020) Genomic diversity and evolution, diagnosis, prevention, and therapeutics of the pandemic COVID-19 disease. PeerJ, 8: e9689.

5. Reid, A.H., Fanning, T.G., Hultin, J.V. and Taubenberger, J.K. (1999) Origin and evolution of the 1918 "Spanish" influenza virus hemagglutinin gene. Proc. Natl. Acad. Sci., 96(4): 1651-1656.

6. Wee, S.L., McNeil, D. and Hernández, J.C. (2020) WHO Declares Global Emergency as Wuhan Coronavirus Spreads. New York Times 30. World Health Organization, Geneva.

7. Islam, M.R., Hoque, M.N., Rahman, M.S., Alam, A.R., Akther, M., Puspo, J.A., Akter, S., Sultana, M., Crandall, K.A. and Hossain, M.A. (2020) Genome-wide analysis of SARS-CoV-2 virus strains circulating worldwide implicates heterogeneity. Sci. Rep., 10(1): 14004.

8. Zhang, T., Wu, Q. and Zhang, Z. (2020) Probable pangolin origin of SARS-CoV-2 associated with the COVID-19 outbreak. Curr. Biol., 30(7): 1346-1351.

9. Koopmans, M. (2021) SARS-CoV-2 and the human-animal interface: Outbreaks on mink farms. Lancet Infect. Dis., 21(1): 18-19.

10. Cutler, S.J., Fooks, A.R. and Van der Poel, W.H. (2010) Public health threat of new, re-emerging, and neglected zoonoses in the industrialized world. Emerg. Infect. Dis., 16(1): 1-7.

11. Caceres, P., Tizzani, P., Ntsama, F. and Mora, R. (2020) The World Organisation for Animal Health: Notification of animal diseases. Rev. Sci. Tech., 39(1): 289-297.

12. Ruckert, A., Zinszer, K., Zarowsky, C., Labonté, R. and Carabin, H. (2020) What role for one health in the COVID19 pandemic? Can. J. Public Health, 111(5): 641-644.

13. Panda, S., Bhargava, B. and Gupte, M.D. (2021) One world one health: Widening horizons. Indian J. Med. Res., 153(3): 241-243.

14. Kelly, T.R., Machalaba, C., Karesh, W.B., Crook, P.Z., Gilardi, K., Nziza, J., Uhart, M.M., Robles, E.A., Saylors, K., Joly, D.O. and Monagin, C. (2020) Implementing One Health approaches to confront emerging and re-emerging zoonotic disease threats: Lessons from PREDICT. One Health Outlook, 2(1): 1-7.

15. Hossain, M.J., Gurley, E.S., Montgomery, J.M., Bell, M., Carroll, D.S., Hsu, V.P., Formenty, P., Croisier, A., Bertherat, E., Faiz, M.A. and Azad, A.K. (2008) Clinical presentation of Nipah virus infection in Bangladesh. Clin. Infect. Dis., 46(7): 977-984.

16. Zumla, A., Hui, D.S. and Perlman, S. (2015) Middle East respiratory syndrome. Lancet, 386(9997): 995-1007.

17. Delgado-Roche, L. and Mesta, F. (2020) Oxidative stress as key player in severe acute respiratory syndrome coronavirus (SARS-CoV) infection. Arch. Med. Res., 51(5): 384-387.

18. Wardeh, M., Sharkey, K.J. and Baylis, M. (2020) Integration of shared-pathogen networks and machine learning reveals the key aspects of zoonoses and predicts mammalian reservoirs. Proc. Royal Soc. B, 287: 20192882.

19. Consortium, P. (2014) Reducing Pandemic Risk, Promoting Global Health. One Health Institute, University of California, Davis, CA.

20. Ihekweazu, C., Michael, C.A., Nguku, P.M., Waziri, N.E., Habib, A.G., Muturi, M., Olufemi, A., DzikwiEmennaa, A.A., Balogun, M.S., Visa, T.I. and Dalhat, M.M.
(2021) Prioritization of zoonotic diseases of public health significance in Nigeria using the one-health approach. One Health, 13: 100257.

21. Ferri, M. and Lloyd-Evans, M. (2021) The contribution of veterinary public health to the management of the COVID19 pandemic from a one health perspective. One Health, 12: 100230 .

22. Basu, A. and Sandhu, H. (2021) International conventions and one health. Indian J. Med. Res., 153(3): 253-255.

23. Machalaba, C.C., Salerno, R.H., Behravesh, C.B., Benigno, S., Berthe, F.C., Chungong, S., Duale, S., Echalar, R., Karesh, W.B., Ormel, H.J. and Pelican, K. (2018) Institutionalizing one health: From assessment to action. Health Secur, 16(S1): S37-S43.

24. Brizee, S., Budeski, K., James, W., Nalabandian, M., Bleijs, D.A., Becker, S.J., Wallace-Sankarsingh, S., Ahumibe, A., Agogo, E., Ihekweazu, C. and Nikkari, S. (2019) Accelerating action in global health security: Global biosecurity dialogue as a model for advancing the global health security agenda. Health Secur., 17(6): 495-503.

25. Rios, R.S., Zheng, K.I. and Zheng, M.H. (2020) Data sharing during COVID-19 pandemic: What to take away. Expert. Rev. Gastroenterol. Hepatol., 14(12): 1125-1130.

26. Besançon, L., Peiffer-Smadja, N., Segalas, C., Jiang, H., Masuzzo, P., Smout, C., Billy, E., Deforet, M. and Leyrat, C. (2021) Open science saves lives: Lessons from the COVID19 pandemic. BMC Med. Res. Methodol., 21(1): 117.

27. Contini, C., Di Nuzzo, M., Barp, N., Bonazza, A., De Giorgio, R., Tognon, M. and Rubino, S. (2020) The novel zoonotic COVID-19 pandemic: An expected global health concern. J. Infect. Dev. Ctries., 14(3): 254-264.

28. Huremović, D. (2019) Brief history of pandemics (pandemics throughout history). In: Psychiatry of Pandemics. Springer, Berlin. p7-35.

29. Habicht, M.E., Eppenberger, P.E. and Rühli, F. (2021) A critical assessment of proposed outbreaks of plague and other epidemic diseases in Ancient Egypt. Int. J. Infect. Dis., 103: 217-219.

30. World Health Organization. (2020) Coronavirus Disease (COVID-19). World Health Organization, Geneva. Available from: https://bit.ly/3rnQHy6. Retrieved on 30-11-2021.

31. Kalra, S., Kelkar, D., Galwankar, S.C., Papadimos, T.J., Stawicki, S.P., Arquilla, B., Hoey, B.A., Sharpe, R.P., Sabol, D. and Jahre, J.A. (2014) The emergence of Ebola as a global health security threat: From "lessons learned" to coordinated multilateral containment efforts. J. Glob. Infect. Dis., 6(4): 164.

32. Dawood, F.S., Iuliano, A.D., Reed, C., Meltzer, M.I., Shay, D.K., Cheng, P.Y., Bandaranayake, D., Breiman, R.F., Brooks, W.A., Buchy, P. and Feikin, D.R. (2012) Estimated global mortality associated with the first 12 months of 2009 pandemic influenza A H1N1 virus circulation: A modelling study. Lancet Infect. Dis., 12(9): 687-695.

33. Tarantola, D. and Henderson, D.A. (2016), Smallpox eradicator. Am. J. Public Health, 106(11): 1895.

34. Cohen, M.S., Hellmann, N., Levy, J.A., DeCock, K. and Lange, J. (2008) The spread, treatment, and prevention of HIV-1: Evolution of a global pandemic. J. Clin. Investig., 118(4): 1244-1254.

35. DeWitte, S.N. (2014) Mortality risk and survival in the aftermath of the medieval Black Death. PLoS One, 9(5): e96513.

36. Horgan, J. (2014) Justinian's Plague (541-542 CE). Ancient History Encyclopedia. Available from: https://bit.ly/3pjMYz9, Retrieved on 30-11-2021.

37. Littman, R.J. (2009) The plague of Athens: Epidemiology and paleopathology. Mt. Sinai. J. Med., 76(5): 456-467.

38. Sabbatani, S. and Fiorino, S. (2009) The antonine plague and the decline of the Roman Empire. Le InfezioniMed., 17(4): 261-275.

39. Taubenberger, J.K., Kash, J.C. and Morens, D.M. (2019) 
The 1918 influenza pandemic: 100 years of questions answered and unanswered. Sci. Transl. Med., 11(502): eaau5485.

40. Peiris, J.S., Lai, S.T., Poon, L.L., Guan, Y., Yam, L.Y., Lim, W., Nicholls, J., Yee, W.K., Yan, W.W., Cheung, M.T. and Cheng, V.C. (2003) Coronavirus as a possible cause of severe acute respiratory syndrome. Lancet, 361(9366): 1319-1325.

41. Keni, R., Alexander, A., Nayak, P.G., Mudgal, J. and Nandakumar, K. (2020) COVID-19: Emergence, spread, possible treatments, and global burden. Front. Pub. Health, $8: 216$.

42. Salyer, S.J., Silver, R., Simone, K. and Behravesh, C.B. (2017) Prioritizing zoonoses for global health capacity building themes from one health zoonotic disease workshop in 7 countries, 2014-2016. Emerg. Infect. Dis., 23(13): S55.

43. Programme, U.N.E. and Institute, D.L.R. (2020) Preventing the Next Pandemic: Zoonotic Diseases and how to Break the Chain of Transmission. UNEP and ILRI Nairobi.

44. Leibler, J.H., Otte, J., Roland-Holst, D., Pfeiffer, D.U., Magalhaes, R.S., Rushton, J., Graham, J.P. and Silbergeld, E.K. (2009) Industrial food animal production and global health risks: Exploring the ecosystems and economics of avian influenza. Ecohealth, 6(1): 58-70.

45. Rockx, B., Kuiken, T., Herfst, S., Bestebroer, T., Lamers, M.M., Munnink, B.B., De Meulder, D., Van Amerongen, G., Van Den Brand, J., Okba, N.M. and Schipper, D. (2020) Comparative pathogenesis of COVID19, MERS, and SARS in a nonhuman primate model. Science, 368(6494): 1012-1015.

46. World Health Organization. (2020) Coronavirus Disease (COVID-19): Situation Report, No. 169. World Health Organization, Geneva.

47. National Research Council (US) Committee on Achieving Sustainable Global Capacity for Surveillance and Response to Emerging Diseases of Zoonotic Origin. (2010) Sustaining Global Surveillance and Response to Emerging Zoonotic Diseases. National Academies Press US, Washington DC.

48. Espinosa, R., Tago, D. and Treich, N. (2020) Infectious diseases and meat production. Environ. Resour. Econ., 76: 1019-1044.

49. Civitello, D.J., Cohen, J., Fatima, H., Halstead, N.T., Liriano, J., McMahon, T.A., Ortega, C.N., Sauer, E.L., Sehgal, T., Young, S. and Rohr, J.R. (2015) Biodiversity inhibits parasites: Broad evidence for the dilution effect. Proc. Natl. Acad. Sci., 112(28): 8667-8671.

50. Hassell, J.M., Begon, M., Ward, M.J. and Fèvre, E.M. (2017) Urbanization and disease emergence: dynamics at the wildlife-livestock-human interface. Trends Ecol. Evol., 32(1): 55-67.

51. Rohr, J.R., Barrett, C.B., Civitello, D.J., Craft, M.E., Delius, B., DeLeo, G.A., Hudson, P.J., Jouanard, N., Nguyen, K.H., Ostfeld, R.S. and Remais, J.V. (2019) Emerging human infectious diseases and the links to global food production. Nat. Sustain., 2: 445-456.

52. El-Sayed, A. and Kamel, M. (2020) Climatic changes and their role in emergence and re-emergence of diseases. Environ. Sci. Pollut. Res. Int., 27(18): 22336-22352.

53. Thompson, A.A., Matamale, L. and Kharidza, S.D. (2012) Impact of climate change on children's health in Limpopo Province, South Africa. Int. J. Environ. Res. Public Health, 9(3): 831-854.

54. El-Sayed, A. and Awad, W. (2018) Brucellosis: Evolution and expected comeback. Int. J. Vet. Sci. Med., 6(Suppl): S31-S35.

55. Newman, A., Smith, D., Ghai, R.R., Wallace, R.M., Torchetti, M.K., Loiacono, C., Murrell, L.S., Carpenter, A., Moroff, S., Rooney, J.A. and Behravesh, C.B. (2020) First reported cases of SARS-CoV-2 infection in companion animals New York, March April 2020. Morbidity and Mortality Weekly Report, No. 69. p710.

56. Messenger, A.M., Barnes, A.N. and Gray, G.C. (2014)
Reverse zoonotic disease transmission (zooanthroponosis): A systematic review of seldom-documented human biological threats to animals. PLoS One, 9(2): e89055.

57. Ewers, C., Grobbel, M., Stamm, I., Kopp, P.A., Diehl, I., Semmler, T., Fruth, A., Beutlich, J., Guerra, B., Wieler, L.H. and Guenther, S. (2010) Emergence of human pandemic O25: H4-ST131 CTX-M-15extended-spectrum- $\beta$ lactamase-producing Escherichia coli among companion animals. J. Antimicrob. Chemother., 65(4): 651-660.

58. Nelson, M.I. and Vincent, A.L. (2015) Reverse zoonosis of influenza to swine: new perspectives on the human-animal interface. Trends Microbiol., 23(3): 142-153.

59. Yoo, S.J., Kwon, T. and Lyoo, Y.S. (2018) Challenges of influenza $A$ viruses in humans and animals and current animal vaccines as an effective control measure. Clin. Exp. Vaccine Res., 7(1): 1-15.

60. Assessment, R.R. (2020) Detection of new SARS-CoV-2 variants related to mink. Eur. Cent. Dis. Prev. Control, https://www.ecdc.europa.eu/sites/default/files/documents/ RRA-SARS-CoV-2-in-mink-12-nov-2020.pdf. Retreived on 30-01-2022.

61. Olival, K.J., Cryan, P.M., Amman, B.R., Baric, R.S., Blehert, D.S., Brook, C.E., Calisher, C.H., Castle, K.T., Coleman, J.T., Daszak, P. and Epstein, J.H. (2020) Possibility for reverse zoonotic transmission of SARSCoV-2 to free-ranging wildlife: A case study of bats. PLoS Pathog., 16(9): e1008758.

62. McAloose, D., Laverack, M., Wang, L., Killian, M.L., Caserta, L.C., Yuan, F., Mitchell, P.K., Queen, K., Mauldin, M.R., Cronk, B.D. and Bartlett, S (2020) From people to Panthera: Natural SARS-CoV-2 infection in tigers and lions at the Bronx Zoo. Mbio, 11(5): e02220-20.

63. Yoo, H.S. and Yoo, D. (2020) COVID-19 and veterinarians for one health, zoonotic-and reverse-zoonotic transmissions. J. Vet. Sci., 21(3): e51.

64. Gruetzmacher, K., Karesh, W.B., Amuasi, J.H., Arshad, A., Farlow, A., Gabrysch, S., Jetzkowitz, J., Lieberman, S., Palmer, C., Winkler, A.S. and Walzer, C. (2021) The Berlin principles on one health-Bridging global health and conservation. Sci. Total Environ., 764: 142919.

65. Mackenzie, J.S. and Jeggo, M. (2019) The One Health Approach why is it so Important? Multidisciplinary Digital Publishing Institute, Basel, Switzerland.

66. Menna, L.F., Santaniello, A., Todisco, M., Amato, A., Borrelli, L., Scandurra, C. and Fioretti, A. (2019) The human-animal relationship as the focus of animal-assisted interventions: A one health approach. Int. J. Environ. Res. Public Health, 16(19): 3660.

67. Machalaba, C., Raufman, J., Anyamba, A., Berrian, A.M., Berthe, F.C., Gray, G.C., Jonas, O., Karesh, W.B., Larsen, M.H., Laxminarayan, R. and Madoff, L.C. (2021) Applying a one health approach in global health and medicine: Enhancing involvement of medical schools and global health centers. Ann. Glob. Health, 87(1): 30.

68. Iatridou, D., Bravo, A. and Saunders, J. (2021) One health interdisciplinary collaboration in veterinary education establishments in Europe: Mapping implementation and reflecting on promotion. J. Vet. Med. Educ., 48(4): 427-440.

69. Kahn, L.H. (2020) Commentary: A one health approach to coronaviruses. Int. J. Epidemiol., 49(3): 728-730.

70. Conrad, P.A., Meek, L.A. and Dumit, J. (2013) Operationalizing one health approach to global health challenges. Comp. Immunol. Microbiol. Infect. Dis., 36(3): 211-216.

71. Gebreyes, W.A., Dupouy-Camet, J., Newport, M.J., Oliveira, C.J., Schlesinger, L.S., Saif, Y.M., Kariuki, S., Saif, L.J., Saville, W., Wittum, T. and Hoet, A. (2014) The global one health paradigm: Challenges and opportunities for tackling infectious diseases at the human, animal, and environment interface in low-resource settings. PLoS Negl. Trop. Dis., 8: e3257.

72. Munyua, P.M., Njenga, M.K., Osoro, E.M., Onyango, C.O., 
Bitek, A.O., Mwatondo, A., Muturi, M.K., Musee, N., Bigogo, G., Otiang, E. and Ade, F. (2019) Successes and challenges of the One Health approach in Kenya over the last decade. BMC Public Health, 19(Suppl 3): 465.

73. Haque, A. (2021) The COVID-19 pandemic and the role of responsible leadership in health care: Thinking beyond employee well-being and organisational sustainability. Leadersh. Health Serv. (Bradf Engl), 34(1): 52-68.

74. Uehlinger, F.D., Freeman, D.A. and Waldner, C.L. (2019) The one health leadership experience at the University of Saskatchewan, Canada. J. Vet. Med. Educ., 46(2): 172-183.

75. Errecaborde, K.M., Macy, K.W., Pekol, A., Perez, S., O’Brien, M.K., Allen, I., Contadini, F., Lee, J.Y., Mumford, E., Bender, J.B. and Pelican, K. (2019) Factors that enable effective one health collaborations-a scoping review of the literature. PLoS One, 14(12): e0224660.

76. Henley, P., Igihozo, G. and Wotton, L. (2021) One health approaches require community engagement, education, and international collaborations a lesson from Rwanda. Nat. Med., 27(6): 947-948.

77. Rabinowitz, P.M., Natterson-Horowitz, B.J., Kahn, L.H., Kock, R. and Pappaioanou, M. (2017) Incorporating one health into medical education. BMC Med. Educ., 17(1): 45.

78. Counotte, M.J. (2021) Zika Virus: Causality, Open Science and Risk of Emerging Infectious Diseases. University Library.

79. Jorge, V.D.A. and Albagli, S. (2020) Research data sharing during the Zika virus public health emergency. Inform. Res., 25(1): 846.

80. Islam, M.T., Croll, D., Gladieux, P., Soanes, D.M., Persoons, A., Bhattacharjee, P., Hossain, M.S., Gupta, D.R. Rahman, M.M., Mahboob, M.G., Cook, N., Salam M.U., Surovy, M.Z., Sancho, V.B., Maciel, J.L.N., NhaniJúnior, A., Castroagudín, V.L., de Assis Reges, J.T., Ceresini, P.C., Ravel, S., Kellner, R., Fournier, E., Tharreau, D., Lebrun, M.H., McDonald, B.A., Stitt, T., Swan, D.,
Talbot, N.J., Saunders, D.G.O., Win, J., and Kamoun, S. (2016) Emergence of wheat blast in Bangladesh was caused by a South American lineage of Magnaporthe oryzae. BMC Biol., 14: 84.

81. Kamoun, S., Talbot, N.J., Islam, M.T. (2019) Plant health emergencies demand open science: Tackling a cereal killer on the run. PLoS Biol. 17(6): e3000302.

82. Coker, R., Rushton, J., Mounier-Jack, S., Karimuribo, E., Lutumba, P., Kambarage, D., Pfeiffer, D.U., Stärk, K. and Rweyemamu, M. (2011) Towards a conceptual framework to support one-health research for policy on emerging zoonoses. Lancet Infect. Dis., 11(4): 326-331.

83. Lebov, J., Grieger, K., Womack, D., Zaccaro, D., Whitehead, N., Kowalcyk, B. and MacDonald, P.D.M. (2017) A framework for one health research. One Health, 3 : 44-50.

84. Nyatanyi, T., Wilkes, M., McDermott, H., Nzietchueng, S., Gafarasi, I., Mudakikwa, A., Kinani, J.F., Rukelibuga, J., Omolo, J., Mupfasoni, D. and Kabeja, A. (2017) Implementing one health as an integrated approach to health in Rwanda. BMJ Glob. Health, 2(1): e000121.

85. Mwacalimba, K.K. and Green, J. (2015) One health'and development priorities in resource-constrained countries: Policy lessons from avian and pandemic influenza preparedness in Zambia. Health Policy Plan., 30(2): 215-222.

86. Dahal, R., Upadhyay, A. and Ewald, B. (2017) One health in South Asia and its challenges in implementation from a stakeholder perspective. Vet. Record, 181(23): 626-626.

87. Fish, R., Austin, Z., Christley, R., Haygarth, P.M., Heathwaite, L.A., Latham, S., Medd, W., Mort, M., Oliver, D.M., Pickup, R. and Wastling, J.M. (2011) Uncertainties in the governance of animal disease: An interdisciplinary framework for analysis. Philos. Trans. R. Soc. Lond. B Biol. Sci., 366(1573): 2023-2034.

88. Bhatia, R. (2019) Implementation framework for one health approach. Indian J. Med. Res., 149(3): 329-331. 